\title{
THE EFFECT OF NEUROHYPOPHYSEAL HORMONES ON THE PERMEABILITY OF THE TOAD BLADDER TO UREA*
}

\author{
BY ROY H. MAFFLY, $\dagger$ RICHARD M. HAYS, $\ddagger$ EZRA LAMDIN § AND \\ ALEXANDER LEAF $\|$ \\ (From the Departments of Medicine, Massachusetts General Hospital and the Harvard Medical \\ School, Boston, Mass., and the Howard Hughes Medical Institute)
}

(Submitted for publication October 27, 1959; accepted November 20, 1959)

With the introduction of the countercurrent hypothesis (1) to explain renal concentrating ability there has been renewed interest in the role of urea in renal tubular function. Recent studies (2-5) suggest that urea makes a major contribution to the urinary concentrating mechanism. If this is the case, one might expect important differences in the permeability of the renal tubule to urea in the presence or absence of antidiuretic hormone. Further, such movement of urea across the tubule might be passive, or effected by means of an active transport system, such as has been described for the bull frog kidney (6-8).

The difficulty of exploring such problems in the intact mammalian kidney need not be emphasized. It would be desirable to use a simpler system, in which the movement of urea across living cells could be measured directly. The studies of Ussing, Zerahn, Koefoed-Johnsen, and Andersen (9-12) have demonstrated the usefulness of isolated, surviving amphibian membranes as models for the study of active transport and other membrane phenomena. In the studies reported below we have used the toad bladder, a tissue that resembles the mammalian renal tubule in several respects (13).

* Supported by grants from the John A. Hartford Foundation, Inc., the United States Public Health Service (Grant H-2822 of the National Heart Institute), and the American Heart Association, Inc.

† United States Public Health Service Postdoctorate Research Fellow 1958-1960. Present address: Cardiovascular Research Institute, University of California Medical Center, San Francisco, Calif.

$\$$ Postdoctorate Fellow of the American College of Physicians 1958-1959 and currently Postdoctorate Research Fellow of the American Heart Association, Inc.

$\S$ Clinical Investigator, Veterans Administration. Present address: Boston Veterans Administration Hospital, Boston, Mass.

|| Investigator, Howard Hughes Medical Institute.
Our results indicate that: 1) the permeability of the toad bladder to urea is low but increases strikingly in the presence of mammalian neurohypophyseal hormones; 2) there is no evidence for active transport of urea across the toad bladder ; 3) the enhanced diffusion of urea following hormone appears to be a result primarily of the increased permeability of the mucosal surface of the membrane; 4) although urea movement is passive, the membrane exhibits a high degree of selectivity in that the diffusion of compounds structurally similar to urea may not be affected by neurohypophyseal hormones.

\section{METHODS AND MATERIALS}

Studies were carried out with the toad, Bufo marinus. The animals were used throughout the year, being kept on moist earth at room temperature and force-fed with meal worms once or twice weekly. A previous publication from this laboratory (13) outlines the general techniques employed, and describes the histological appearance of the toad bladder, its electrical properties, and its active transport of sodium ion from the mucosal to the serosal surface which is characteristically stimulated by neurohypophyseal hormones.

In the present studies, the experimental protocol generally observed was as follows: after doubly pithing the toad, one-half of the bilobed urinary bladder was removed through a ventral abdominal incision, rinsed in frog Ringer solution, and mounted as a diaphragm separating two halves of a lucite chamber similar in design to that described by Ussing and Zerahn (9). Equal volumes (usually $10 \mathrm{ml}$ ) of Ringer solution bathed each surface of the membrane. In the studies with urea, $0.1 \mathrm{mg}$ per $\mathrm{ml}$ each of penicillin $\mathrm{G}$ and streptomycin sulfate was added to the bathing media to prevent bacterial decomposition of urea, and in most instances sufficient unlabeled urea was added to raise the concentration in the media to 2 mmoles. The spontaneous membrane potential was brought to zero by the short-circuiting technique of Ussing and Zerahn (9). A tracer amount of the radioactive substance to be studied was then added to one 
side of the bladder and its rate of appearance on the other side was determined. From this a permeability coefficient, $\mathrm{K}_{\mathrm{trans}}$, could be obtained which is defined as the amount of the given substance crossing $1 \mathrm{sq} \mathrm{cm}$ of membrane surface per second under a driving force of unit concentration gradient; thus

$$
\mathrm{K}_{\text {trans }}=\frac{\text { increase in counts on the unlabeled side }}{\text { concentration of counts on labeled side } \times \text { area of membrane } \times \text { time }} \text {, }
$$

and has the dimensions of centimeters per second. In describing the statistics of any series of measurements, (SE) will be used to designate standard error of the mean and (SD) the standard deviation.

In general, control observations were made for two half hour periods, after which neurohypophyseal hormone was added and measurements continued for two further periods. All experiments were carried out well within the period of viability of the tissue which, as judged by relative constancy of the short-circuit current, is at least 6 hours.

In the studies designed to evaluate the possibility of active transport of urea, double labeling experiments were carried out with $\mathrm{N}^{15}$ - and $\mathrm{C}^{14}$-labeled urea added to opposite bathing media; 50 to $200 \mathrm{mg}$ of $\mathrm{N}^{15}$-urea was used per study (final total urea concentration of 40 to 330 mmoles) and a corresponding amount of unlabeled compound was therefore added to the opposite side together with the tracer amounts of $\mathrm{C}^{\mathbf{1 4}}$-urea in order to equalize the concentrations of urea bathing the two surfaces of the membrane. In this group of studies, neurohypophyseal hormones were either not added or else were introduced at the beginning of the experiment.

To assess a possible role of carrier-mediated transport of urea, vasopressin was administered to the short-circuited bladder and the permeability to $\mathrm{C}^{\mathbf{1 4}}$-urea added to the mucosal side was measured. Following an initial half hour control period, sufficient unlabeled urea was added to the mucosal medium to bring the total concentration of urea to 25 or 50 mmoles, and measurements were continued for ${ }^{\circ}$ a second and third half hour period.

To determine the amount of labeling of tissue water by urea, paired halves of the same bladder were mounted in two separate chambers and permeability studies were carried out as usual, except that $\mathrm{C}^{14}$-urea was added to the mucosal side only, and vasopressin was administered to only one of the paired halves. At the end of the experiment, the bathing solutions were removed and the tissues carefully blotted on Whatman no. 54 filter paper in such a way as to avoid contamination of the serosal surface by the isotope-containing mucosal fluid. The tissue was quickly weighed (B-6 semi-micro balance, Mettler Instrument Corp., Hightstown, N. J.) and then homogenized with $0.25 \mathrm{ml}$ of 10 per cent trichloroacetic acid; the homogenate was diluted with $3.0 \mathrm{ml}$ of Ringer's solution and then centrifuged for 20 minutes at approximately $4,000 \mathrm{rpm}$. The activity of $\mathrm{C}^{14}$ in the supernatant fluid was determined. The water content of the blotted toad bladder, considered to be equal to the loss in weight occurring after drying at $95^{\circ} \mathrm{C}$ for 24 hours, averaged
$80.8 \pm 1$ per cent $(\mathrm{SD})$ in 28 measurements, ${ }^{1}$ and hence a figure of 81 per cent was utilized to calculate the concentration of labeled urea in the total tissue water. The concentration of $\mathrm{C}^{14}$-urea in tissue water divided by its concentration in the bathing medium, times 100 , has been termed "per cent labeling."

The neurohypophyseal material used was commercial vasopressin (Pitressin, Parke, Davis and Co., Detroit, Mich.) 0.05 to 0.2 unit per $\mathrm{ml}$ of bathing medium and, in a few experiments, purified oxytocin ( 0.02 unit per $\mathrm{ml})$ and arginine-vasopressin (0.0085 unit per $\mathrm{ml})$, the latter kindly furnished by $\mathrm{Dr}$. Vincent du Vigneaud. The effects of neurohypophyseal preparations tested were qualitatively similar and the term "hormone" will be used subsequently to refer to these preparations. Isotopes used were urea- $C^{14}$, acetamide- $1-C^{14}$, thiourea- $S^{35}$, and water $-\mathrm{H}^{3}$ (New England Nuclear Corp., Boston, Mass.) ; urea- $\mathrm{N}^{15}$ (Isomet Corp., Palisades Park, N. J. and Abbott Laboratories, North Chicago, Ill.) ; thiourea$\mathrm{C}^{14}$ (Nuclear-Chicago Corp., Chicago, I1l. and New England Nuclear Corp.); L-arginine- $C^{14}$, choline-methyl- $C^{14}$, glycerol-1- $C^{14}$, glycine-1- $C^{14}$, thiocyanate- $S^{33}$, sucrose- $C^{14}$ (uniformly labeled), and DL-lactic-1- $\mathrm{C}^{\mathbf{1 4}}$ acid (NuclearChicago Corp.); inulin carboxylic acid-C ${ }^{14}$ (National Bureau of Standards, Washington, D. C.) ; tritiated 1,5anhydroglusitol (courtesy of Dr. Robert K. Crane); $\mathrm{Na}^{24}, \mathrm{~K}^{12}$ and $\mathrm{Cl}^{35}$ (Atomic Energy Commission, Oak Ridge, Tenn.) ; and $\mathrm{I}^{131}, \mathrm{~S}^{35} \mathrm{O}_{4}$ and colloidal gold, $\mathrm{Au}^{188}$ (Abbott Laboratories).

Routine counting of radioactive isotopes was performed with a gas-flow, thin-window counter (automatic sample changer, model 750, Baird-Atomic Instrument, Inc., Cambridge, Mass.). Tritium and a few $\mathrm{C}^{14}$ samples were counted with a Tri-carb liquid scintillation spectrometer (Packard Instruments Co., La Grange, Ill.). Great care was taken to keep self-absorption constant when using the gas-flow counter.

$\mathrm{N}^{15}$-urea was analyzed as $\mathrm{N}^{15}$ gas in a mass spectrometer (model 21-201, Consolidated Electrodynamics Corp., Pasadena, Calif.) after preparation by the following modification of the method of Sprinson and Rittenberg (14) : 0.5 or $1.0 \mathrm{ml}$ of medium containing $\mathrm{N}^{15}$-urea was diluted in a solution of $\mathrm{N}^{14}$-urea to achieve a ratio of $\mathrm{N}^{15}$ : $\mathrm{N}^{14}$ of 0.5 to 3.0 per cent. One $\mathrm{ml}$ of this solution was placed in the outer well of a Conway dish containing $0.07 \mathrm{~N} \mathrm{H}_{2} \mathrm{SO}_{4}$ in the center well. Urease was added to

1 This value agreed satisfactorily with the volume of distribution of tritiated water, which in 4 measurements was found to average 78 per cent. 
TABLE I

Permeability of toad bladder to urea

\begin{tabular}{cccc}
\hline $\begin{array}{c}\text { Neurohypo- } \\
\text { physeal } \\
\text { hormone }\end{array}$ & $\begin{array}{c}\text { Number of } \\
\text { periods }\end{array}$ & \begin{tabular}{l} 
Mean \\
\cline { 3 - 4 } trans
\end{tabular} & $\begin{array}{c}\text { Standard } \\
\text { error } \\
\text { of mean }\end{array}$ \\
\hline Absent & 74 & 26 & 2.5 \\
Present & 41 & 274 & 3.8 \\
\hline
\end{tabular}

hydrolyze the urea to ammonia which was then liberated by potassium carbonate and trapped in the center well as ammonium sulfate. The ammonium sulfate was subsequently treated by the procedure of Sprinson and Rittenberg (14). Appropriate standards were run with each group of samples; the calibration curves so obtained proved to be linear over the range employed.

\section{RESULTS}

Permeability to urea. The permeability coefficient of the toad bladder for urea (Table I) in the absence of hormone, measured in 74 half hour periods carried out in either direction across the membrane, averaged $26 \pm 2.5(\mathrm{SE}) \times 10^{-7} \mathrm{~cm}$ per second. The range of individual values was large, 1.4 to $91 \times 10^{-7} \mathrm{~cm}$ per second.

Upon the addition of hormone to the serosal bathing medium, the permeability rapidly and regularly rose by fivefold to over 100 -fold, reaching a mean value of $274 \pm 3.8(\mathrm{SE}) \times 10^{-7} \mathrm{~cm}$ per second with a range of 165 to $479 \times 10^{-7} \mathrm{~cm}$ per second. A typical response is recorded in Figure 1. No response was noted when hormone was added to the medium bathing the $\mathrm{mu}$ cosal surface, as is also the case for active sodium transport (13).

Specificity of hormonal effect. The effect of hormone on the permeability of the bladder to urea and to other substances is shown in Table II. The bulk of these substances penetrates the bladder at a relatively low rate which is unaffected by hormone. Water, sodium (in the direction of active transport) and urea show an increased penetration of the membrane following hormone. The permeability to water increases approximately twofold, and to sodium two- to threefold. Urea is distinctive by virtue of its relatively low penetration in the absence of hormone and the large augmentation in permeability in the presence of this hormone.

Two compounds, chosen because of their apparent structural similarity to urea have also been tested (see Figure 1). Acetamide, in which one of the amino groups of urea has been replaced by a methyl radical, behaves in a manner very similar to urea both before and after hormone; whereas thiourea, with a sulfur atom replacing the double bonded oxygen of urea, moves in the same permeability range as urea before vasopressin but shows no response whatsoever to the addition of the hormone.

The following facts lend assurance that the striking difference in behavior of urea and thiourea is valid. 1) The marked increase in radioactivity which appeared on the opposite side of the bladder after hormone in an experiment with $\mathrm{C}^{14}$-urea disappeared upon treatment with urease, indicating that the substance that traversed the membrane was indeed urea. 2) Identical values for the flux of thiourea were obtained with two different tracers, $\mathrm{C}^{14}$ - and $\mathrm{S}^{35}$-labeled thiourea, respectively. Both of these compounds were chromatographed on paper using a solvent system of butanol 86 per

TABLE II

Permeability of toad bladder without and with vasopressin

\begin{tabular}{|c|c|c|c|c|}
\hline \multirow[b]{2}{*}{ Substance } & & & \multicolumn{2}{|c|}{$\mathrm{K}_{\text {trans }} \times 10^{-7} \mathrm{~cm} / \mathrm{sec}$} \\
\hline & & & Without vasopressin & With vasopressin \\
\hline Colloidal gold & & & 0 & 0 \\
\hline $\left.\begin{array}{l}\text { Thiourea } \\
\text { Glycerol } \\
\text { 1,5-Anhydroglusitol } \\
\text { Sucrose } \\
\text { Inulin }\end{array}\right\}$ & $\left.\begin{array}{l}\text { Sodium (passive) } \\
\text { Potassium } \\
\text { Choline } \\
\text { Chloride } \\
\text { Iodide }\end{array}\right\}$ & $\left.\begin{array}{l}\text { Thiocyanate } \\
\text { Sulfate } \\
\text { Lactate } \\
\text { Glycine } \\
\text { Arginine }\end{array}\right\}$ & $1-20$ & $1-20$ \\
\hline Sodium (active) & & & 35 & 100 \\
\hline Urea & & & 26 & 274 \\
\hline Water & & & 900 & 1,600 \\
\hline
\end{tabular}




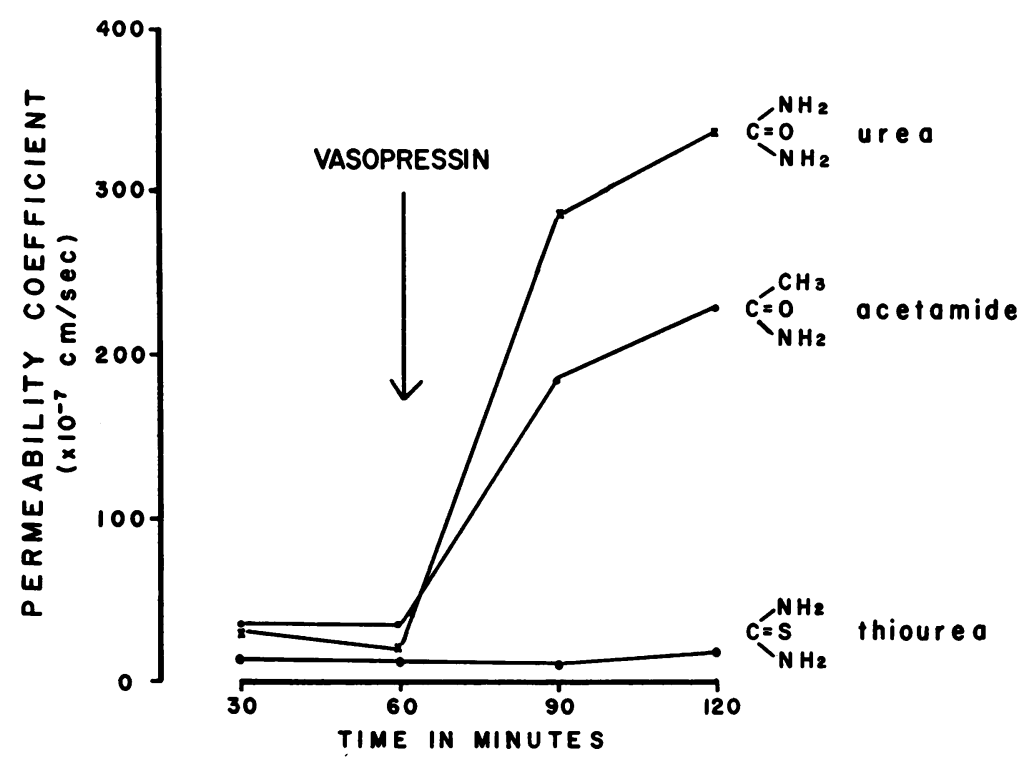

Fig. 1. EFFECT OF NEUROHYPOPHYSEAL HORMONE ON PERMEABILITY OF TOAD BLADDER TO UREA, ACETAMIDE AND THIOUREA. The appropriately labeled molecule was added to the medium bathing one surface of the membrane and its rate of appearance on the opposite side was determined. After two periods of 30 minutes each, vasopressin was added to the serosal medium and an additional two periods determined. In every instance the permeability to urea and acetamide was enhanced by hormone, while permeability to thiourea was unaffected.

cent and water 14 per cent, and both gave single peaks of radioactivity with $R_{\mathbf{f}}$ values of 0.34 to 0.36 . 3) The failure of a hormonal response could not be attributed to inactivation of the hormone by the small amounts of thiourea employed, because in all experiments the usual marked effect of the hormone on the active sodium transport occurred. The hormonal enhancement of urea penetration was also demonstrated in the presence of 1 mmole thiourea in the bathing media.

To determine if the vasopressin effect on urea permeability was contingent upon the presence of sodium transport, urea flux measurements were carried out in the absence of sodium ion by replacing all sodium in frog Ringer with choline. It was found that urea permeability was still markedly enhanced following the hormone although, in the few (four) experiments performed, perhaps not to the same extent as in the presence of sodium.

The mechanism of penetration. Ussing (10) has stated the criterion for determining whether the passage of an ion or molecule through a membrane involves its active transport. If the perme- ability of the membrane for the substance tested is found equal in both directions in the absence of an electrochemical potential gradient for that substance across the membrane and in the absence of net movements of solvent through the membrane, it can reasonably be concluded that active transport of that substance is not taking place. ${ }^{2}$

Such a study was carried out employing $\mathrm{C}^{14}$ urea to determine the permeability in one direction and $\mathrm{N}^{15}$-urea to determine simultaneously the permeability in the other direction. The method has been described in the preceding section. Four experiments, comprising a total of 17 half hour periods, were performed in the absence of hormone. Three experiments, totaling 13 periods, were performed following the introduction of 2 units of vasopressin to both the mucosal and serosal bathing media. The results are shown in Table III. It can be seen that both before and after hormone

2 Even with these conditions fulfilled there remains the possibility that the permeating substance may be actively transported at an equal rate in the two directions across the membrane. Because of the biological futility of membranes' engaging in such symmetrical active transport, this possibility can probably be disregarded. 
TABLE III

Simultaneous permeability coefficients in the two directions through the toad bladder

\begin{tabular}{lccccc}
\hline & & \multicolumn{3}{c}{ Permeability coefficients } & \\
\cline { 3 - 5 } Hormone & $\begin{array}{c}\text { No. of } \\
\text { periods }\end{array}$ & $\begin{array}{c}\mathrm{M} \rightarrow \mathrm{S}^{*}\left(\times 10^{-7} \mathrm{~S} \rightarrow \mathrm{M}^{*}\right. \\
\mathrm{cmec})\end{array}$ & $\Delta$ & SE of $\Delta$ \\
\hline Absent & 17 & 26.0 & 26.8 & 0.8 & \pm 2.3 \\
Present & 13 & 251.3 & 261.2 & 9.9 & \pm 7.9 \\
\hline
\end{tabular}

* Mucosal to serosal and serosal to mucosal permeabilities measured simultaneously with $\mathrm{N}^{15}$ - and $\mathrm{C}^{14}$-labeled urea.

there is no significant difference in the permeability coefficients in the two directions.

In an attempt to learn if carrier-mediated transport is involved in the enhanced flux of urea following hormone, studies were performed to determine if an increase in the concentration of unlabeled urea in the medium would result in depression of permeability to the labeled urea. Both labeled and unlabeled urea were added only to the mucosal medium. As can be seen in the last two columns of Table IV, increasing the concentration of urea to 25 or 50 mmoles was associated with a small decrease in the permeability coefficient as compared with values obtained during the control period, when only tracer amounts of urea were present in the medium. However, as a similar slight decrease with time is shown in the second and third columns, when no unlabeled urea was added, this decrease cannot be attributed to the added urea. The values for each period with or without added urea do not differ significantly.

Site of hormonal action. Evidence has been presented previously $(15,16)$ that the transmembrane permeability barrier presented by the toad bladder can be localized to two functionally

TABLE IV

Absence of self-depression of high permeability to urea after hormone

\begin{tabular}{|c|c|c|c|c|}
\hline \multirow[b]{2}{*}{ Period } & \multicolumn{2}{|c|}{ Without added urea } & \multicolumn{2}{|c|}{ With added urea } \\
\hline & $\begin{array}{c}\mathrm{K}_{\text {trans }} * \\
\left(\times 10^{-7} \mathrm{~cm} /\right. \\
\mathrm{sec})\end{array}$ & $\begin{array}{l}\text { Per cent } \\
\text { of } \\
\text { Period } 1\end{array}$ & $\begin{array}{c}\mathrm{K}_{\mathrm{trans}} * \\
\left(\times 10^{-7} \mathrm{~cm} /\right. \\
\mathrm{sec})\end{array}$ & $\begin{array}{c}\text { Per cent } \\
\text { of } \\
\text { Period } 1\end{array}$ \\
\hline $\begin{array}{l}1 \\
2 \\
3\end{array}$ & $\begin{array}{l}334 \\
292 \\
270\end{array}$ & $\begin{array}{r}100 \\
88 \\
81\end{array}$ & $\begin{array}{l}336 \\
321 \\
262\end{array}$ & $\begin{array}{r}100 \\
95 \\
78\end{array}$ \\
\hline
\end{tabular}

* Mean of 6 experimental values per period. Nonlabeled urea added to mucosal medium at end of first period to yield concentrations of 25 ( 3 experiments) or 50 mmoles (3 experiments). distinct barriers located at or near the mucosal and serosal surfaces, respectively. The mucosal surface was found to be substantially less permeable to lactate ions than was the serosal surface. If these same barriers apply also to urea, the increased transmembrane permeability to urea occurring after hormone must be occasioned by an increase in the permeability of one or both diffusion barriers. Which of these is acted upon can be evaluated by comparing the concentration of $\mathrm{C}^{14}$-urea in tissue water at the conclusion of flux experiments, performed with and without hormone. If labeled urea is placed in the medium bathing one side of the membrane (mucosal side in these experiments) the concentration of the labeled molecules in tissue water when a steady state is approximated will depend upon the relative permeability of the two surfaces. If permeability of the serosal surface is increased by hormone, what $\mathrm{C}^{14}$-urea does pass through the mucosal barrier into the tissue will tend to pass out relatively more quickly across the serosal surface of the bladder treated with hormone. The concentration of $\mathrm{C}^{14}$-urea in tissue water, therefore, will be lower in the hormone-treated than in the paired control bladder. If, on the other hand, the mucosal surface were made more permeable by the hormone, the labeled molecules would enter more quickly into the tissue water, hence the tissue water concentration of $\mathrm{C}^{\mathbf{1 4}}$-urea would be higher in the bladder treated with hormone than in the control. This is schematically depicted in Figure 2.

The technique of measurement using paired bladder halves has been described. The results are summarized in Table V. The per cent labeling of tissue water is listed for paired bladder halves without and with hormone added to the serosal medium, together with the average transmembrane permeability coefficient during the experiment. It will be seen that without hormone, labeling averaged 11 per cent whereas, coincident with the increased flux with the hormone, labeling rose in all experiments, to a mean of 38 per cent.

This increase in concentration of $\mathrm{C}^{\mathbf{1 4}}$-urea in tissue water was not a result simply of the attainment of a higher concentration of $\mathrm{C}^{14}$-urea on the serosal side of the bladder treated with hormone. When the possible contribution from the serosal medium to the tissue activity is estimated, this 
contribution amounts to one-twentieth or less of the observed total tissue activity and was subtracted from the tissue labeling before being included in Table V. In addition, for a direct check, two experiments (Experiments 4 and 5) were performed with sufficient $\mathrm{C}^{14}$-urea added to the serosal bathing medium of the halves without hormone to bring the $\mathrm{C}^{\mathbf{1 4}}$-urea concentration up to or over that attained by the paired treated half, and the results were not significantly affected.

That the activity in the tissue in experiments with urea labeling was still present as urea, and not as some metabolic product, was demonstrated by treating several labeled tissue extracts with
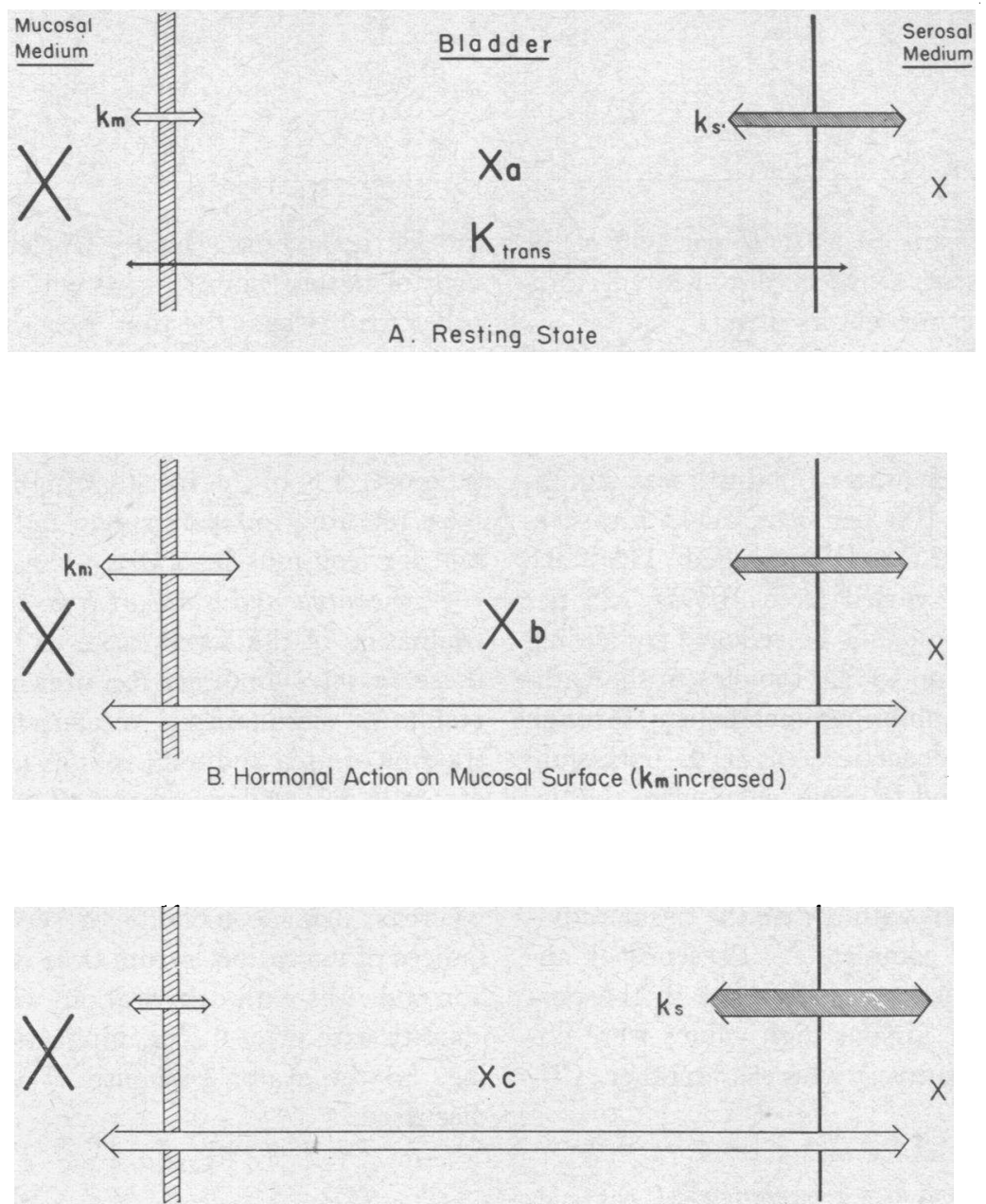

C. Hormonal Action on Serosal Surface ( $k_{\imath}$ increased)

Fig. 2. Schematic diagram to IllUStrate method of Determining at WHICH SURFACE OF MEMBRANE THE NEUROHYPOPHYSEAL HORMONES ACT. Labeled urea, in these experiments, was added to the mucosal bathing medium to yield a concentration of tracer, $X$, in the medium. " $A$ " represents the resting, non-hormone-treated state. " $B$ " shows the increase in the transmembrane permeability coefficient, $K_{t r a n s}$, and of the tissue concentration, $X_{b}$, that would result from an action of the hormone to increase the permeability of the mucosal diffusion barrier, $k_{m}$. A similar increase in $\mathrm{K}_{\mathrm{trans}}$ might be achieved by an action of the hormone to increase the serosal permeability, $k_{\mathbf{s}}$, as is shown in "C", but such an effect would result in a reduction in tissue concentration, $X_{c}$, of the labeled urea. Hence the criterion for a mucosal site of action of the hormone is that $X_{b}>X_{a}$, and for a serosal site of action that $\mathrm{X}_{\mathbf{a}}>\mathrm{X}_{\mathrm{c}}$. 
TABLE V

Labeling of tissue water by $C^{14}$-urea from mucosal surface

\begin{tabular}{|c|c|c|c|c|c|}
\hline \multirow[b]{2}{*}{ Exp. } & \multirow{2}{*}{$\begin{array}{l}\text { Min elapsed } \\
\text { after C14-urea } \\
\text { added }\end{array}$} & \multicolumn{2}{|c|}{$\begin{array}{l}\text { Per cent labeling } \\
\text { Hormone }\end{array}$} & \multicolumn{2}{|c|}{$\begin{array}{c}\mathrm{K}_{\text {trans }}\left({ }_{\text {Hormone }}^{\left(\times 10^{-7} \mathrm{~cm} / \mathrm{sec}\right)}\right. \\
\text { Hor }\end{array}$} \\
\hline & & Absent & Present & Absent & Present \\
\hline $\begin{array}{c}1 \\
2 \\
3 \\
4 \\
5 \\
6 \\
7 \\
8 \\
\text { Mean }\end{array}$ & $\begin{array}{r}72 \\
75 \\
78 \\
89 \\
90 \\
112 \\
122 \\
156\end{array}$ & $\begin{array}{r}22 \\
7 \\
6 \\
5 \\
16 \\
5 \\
14 \\
11 \\
11\end{array}$ & $\begin{array}{l}44 \\
44 \\
47 \\
35 \\
34 \\
43 \\
23 \\
37 \\
38\end{array}$ & $\begin{array}{r}22 \\
15 \\
14 \\
5 \\
30 \\
7 \\
11 \\
36 \\
18\end{array}$ & $\begin{array}{l}418 \\
265 \\
227 \\
300 \\
503 \\
255 \\
324 \\
340 \\
329\end{array}$ \\
\hline
\end{tabular}

urease. By this means, at least 97 per cent of the activity of the tissue extracts disappeared, indicating it was in fact present as urea.

Urea space. When $\mathrm{C}^{14}$-urea was applied to both surfaces of the bladder by immersing the tissue directly in a medium containing $\mathrm{C}^{14}$-urea, the per cent labeling of tissue water obtained was significantly greater than 100 per cent in 42 measurements $(\mathrm{p}=<0.001)$. It averaged $115 \pm 0.8$ (SE) per cent and varied from 103 to 125 per cent. This value could not be reduced by adding nonradioactive urea up to 300 mmoles to the bathing medium or by inhibiting metabolism through exposure to cold iodoacetic acid or to potassium cyanide. It was found to occur even when the tissue had been treated with 10 per cent trichloroacetic acid or by boiling prior to incubation in $\mathrm{C}^{\mathbf{1 4}}$ urea. After treatment with urease the tissue radioactivity disappeared completely. Presence or absence of hormone made no difference in the percentage of labeling. Similar high values were obtained with $\mathrm{C}^{14}$-thiourea, whereas another $\mathrm{C}^{14}$ -

TABLE VI

Osmolalities and urea concentrations of toad serum and urine

\begin{tabular}{|c|c|c|c|c|}
\hline & \multicolumn{2}{|c|}{$\begin{array}{c}\text { Urea con- } \\
\text { centration } \\
(\mathrm{mmoles} / \mathrm{L})\end{array}$} & \multicolumn{2}{|c|}{$\begin{array}{c}\text { Total solute } \\
\text { concentration } \\
(\mathrm{mOsm} / \mathrm{kg} \\
\left.\mathrm{H}_{2} \mathrm{O}\right)\end{array}$} \\
\hline & Serum & Urine & Serum & Urine \\
\hline Individual toads & $\begin{array}{l}44 \\
39 \\
24 \\
21\end{array}$ & $\begin{array}{l}43 \\
40 \\
38 \\
39\end{array}$ & $\begin{array}{l}297 \\
224 \\
204\end{array}$ & $\begin{array}{l}302 \\
287 \\
126 \\
148\end{array}$ \\
\hline \multicolumn{5}{|c|}{ Pooled measurements } \\
\hline $\begin{array}{l}6 \text { toads } \\
5 \text { toads }\end{array}$ & $\begin{array}{l}18 \\
15\end{array}$ & $\begin{array}{l}46 \\
42\end{array}$ & $\begin{array}{l}230 \\
218\end{array}$ & $\begin{array}{r}105 \\
86\end{array}$ \\
\hline
\end{tabular}

labeled compound, lactate, labeled nearly 100 per cent of tissue water, as did tritiated water. With other toad tissues the urea space was lower: heart and colon, 100 per cent; muscle, 105 per cent; but skin reached 109 per cent. We are unable to explain these findings of high labeling at this time although it is of interest that high values have also been reported for mammalian red blood cells (17) and for frog muscles (18).

Urine urea and state of hydration. To permit evaluation of the significance to the intact toad of these in vitro findings for urea permeability, the results of simultaneous measurements of concentrations of urea and total solutes in blood and urine of toads in random states of water balance are shown in Table VI. It can be seen that the urine urea concentration remains relatively constant, whereas, using osmolality of serum and urine as indices of hydration, serum urea drops with hydration and rises with dehydration, when it approaches identity with urine. The implications of these findings to the water economy of the toad will be discussed.

\section{DISCUSSION}

These studies indicate that urea penetrates the toad bladder by passive diffusion, and that this diffusion is markedly increased by neurohypophyseal hormones, which act to increase the permeability of a barrier at or near the mucosal surface.

There are a few animal species in which active transport of urea by the renal tubule appears to take place. Active urea secretion has been shown in the bullfrog (6-8) and has been suggested in the case of certain rodents (19), while active reabsorption of urea occurs in elasmobranchs (20). In general, however, the movement of urea across 
the mammalian renal tubular epithelium has been considered to be by free diffusion (21-23) as our studies indicate to be the case for the toad bladder.

The equal permeability to urea in both directions across the membrane indicates its passage by a passive process. Even in the absence of active transport the possibility of a carrier-mediated transport was considered. When, however, the concentration of unlabeled urea was increased to 50 mmoles in the mucosal bathing medium (a concentration comparable with that present in the bladder urine of the toad in vivo) no evidence of self-depression of the permeability to $\mathrm{C}^{14}$-urea was detected. However, at these concentrations of urea a "carrier" might still be incompletely saturated. Urea is known to form hydrogen bonds with great facility (24). For example, one molecule of mercaptoalbumin has been estimated to bind some 2,000 urea molecules (25) or double its own weight. Hence, if a carrier for urea actually existed, which depended upon hydrogen bonding, its capacity might conceivably be quite large, and the concentrations of urea utilized in our study might then have been too low to test adequately for competition. To exclude this possibility, studies at much higher urea concentrations would have to be performed. When higher ambient urea concentrations were employed, however, interpretation of the results was complicated by apparent deterioration of the membrane.

It appears most likely that urea moves through the toad bladder in aqueous channels. This is suggested by the solubility properties of the compound; urea is much more soluble in water than in lipid solvents. Collander and Bärlund (26) found the partition coefficients for urea in ether: water and olive oil: water systems to be 0.00047 and 0.00015 , respectively. Similar values (averaging 0.0007 ) have been obtained in this laboratory with $\mathrm{C}^{14}$-urea in a hexane: Ringer solution system. Also consistent with the notion that urea moves in aqueous channels are the observations regarding the relative permeability coefficients for water and urea through the membrane. In the absence of hormone, the permeability coefficient for urea is low, approximating that of a large group of substances tested. Water penetrates at a much greater rate, approximately $900 \times 10^{-7} \mathrm{~cm}$ per second. With hormone, however, the percentage increase in permeability to urea rises sharply, much more than does that to water. Hence, the ratio of the permeability coefficients for urea and water, which was approximately $1: 36$ before hormone, rises to $1: 6$ after hormone. At $25^{\circ} \mathrm{C}$ the aqueous free diffusion coefficient for urea is $137 \times 10^{-7} \mathrm{~cm}^{2}$ per second (27), and for water is $246 \times 10^{-7} \mathrm{~cm}^{2}$ per second ${ }^{3}(28)$ or a ratio of $1: 2$. It is thus apparent that in the presence of hormone the ratio of the permeabilities to urea and water begins to approach that expected if both are penetrating the membrane by diffusion through aqueous channels.

Koefoed-Johnsen and Ussing (11) have presented convincing evidence that neurohypophyseal hormones increase the permeability of the toad skin to water by dilating aqueous pores. If such is also the case for the toad bladder and if it is assumed that, following hormone, channels previously accessible only to water become accessible also to urea so that the bulk of the post-hormonal diffusion is occurring through these dilated channels, the data indicate that urea is hindered in these channels to a greater extent than is water, by a factor of about three. If, on the other hand, one makes the assumption that the effect of the hormone is just to open up or otherwise make available channels previously inaccessible to both urea and water, then the increase in permeability occurring with the hormone will reflect the relative ease with which the two molecules diffuse through these new channels. The increases found were for urea, $248 \times 10^{-7} \mathrm{~cm}$ per second and for water, $700 \times 10^{-7} \mathrm{~cm}$ per second or a ratio of $1: 2.8$, which approaches the $1: 2$ ratio of their free diffusion coefficients.

The increase in the transmembrane permeability and in tissue labeling with $\mathrm{C}^{14}$-urea which occurs across the mucosal surface following the administration of hormone indicates that the relative permeability of a mucosal barrier has been increased. We may ask whether this is an effect purely on a mucosal barrier, or whether in addition there has

3 The fact that the permeability coefficient and the free diffusion coefficient are in the same absolute range does not mean that urea and water are unhindered by the membrane. Diffusion coefficients are based on a barrier thickness of $1 \mathrm{~cm}$ of solvent, whereas permeability coefficients ignore the thickness of the barrier. Since the mucosa of the distended toad bladder may be approximately $30 \mu(0.003 \mathrm{~cm})$ thick, its "diffusion resistance" to urea in the presence of hormone is still some 175 times greater than that of a comparable thickness of water. 
been a change in the permeability of the serosal barrier. This question can be approached, but not resolved at the present time, by a more detailed consideration of the two permeability barriers and their relation to the transmembrane permeability.

If the mucosal bathing medium is labeled and the labeled substance penetrates the membrane passively, then when a steady state is reached the net fluxes of the substance across the mucosal permeability barrier, across the serosal permeability barrier, and across the entire membrane, will be equal. That is,

$$
\left(\mathrm{C}_{\mathrm{m}}-\mathrm{C}_{\mathrm{c}}\right) \mathrm{k}_{\mathrm{m}}=\left(\mathrm{C}_{\mathrm{c}}-\mathrm{C}_{\mathrm{s}}\right) \mathrm{k}_{\mathrm{s}}=\left(\mathrm{C}_{\mathrm{m}}-\mathrm{C}_{\mathrm{s}}\right) \mathrm{K}_{\text {trans }} \text {, }
$$

where $C_{m}, C_{s}$, and $C_{c}$ are the concentrations of the substance in the mucosal medium, the serosal medium, and the cell water contained within the barriers, respectively, and $k_{m}, k_{s}$, and $K_{\text {trans }}$ are the permeability coefficients of the mucosal barrier, the serosal barrier, and the entire membrane, respectively. Since $C_{\mathbf{s}}$ is essentially zero, the second and third equalities reduce to

$$
\mathrm{C}_{\mathrm{c}} \mathrm{k}_{\mathrm{s}}=\mathrm{C}_{\mathrm{m}} \mathrm{K}_{\text {trans }} \text {. Rearranging, } \mathrm{k}_{\mathrm{s}}=\frac{\mathrm{K}_{\text {trans }}}{\frac{\mathrm{C}_{\mathrm{c}}}{\mathrm{C}_{\mathrm{m}}}} \text {. }
$$

We have termed the fraction $\frac{C_{c}}{C_{m}} \times 100$ the per cent labeling from the mucosal surface.

$$
\text { Therefore, } k_{s}=\frac{K_{\text {trans }}}{\text { per cent labeling }} \times 100 .
$$

A similar expression for $\mathrm{k}_{\mathrm{m}}$ can be derived :

$$
\mathrm{k}_{\mathrm{m}}=\frac{\mathrm{K}_{\mathrm{trans}}}{100 \text { per cent labeling }} \times 100 .
$$

The presence or absence of change in $k_{\mathbf{s}}$ following hormone will therefore be reflected in the relative change of $\mathrm{K}_{\text {trans }}$ to that of the per cent labeling. However, arriving at an accurate value for $k_{8}$ requires in turn an accurate value for $\mathrm{C}_{\mathrm{c}}$, the concentration of $\mathrm{C}^{\mathbf{1 4}}$-urea in the tissue water within the two permeability barriers, and several complicating factors obscure the latter's true value:

1. There is a significant inulin space on the mucosal aspect of the bladder which is in equilibrium with the labeled urea of the mucosal medium. Thus, mucosal labeling studies with $\mathrm{C}^{14}$ inulin performed in a manner identical with those for $\mathrm{C}^{14}$-urea have revealed a variable labeling (unaffected by hormone) of 0 to 16 per cent, averaging
7 per cent in nine experiments. Presumably this is all external to the mucosal permeability barrier, since inulin characteristically occupies an extracellular position in tissues. Hence the per cent labeling of urea which is applicable in the equation for $k_{\mathrm{g}}$ is too large by this variable amount. If the urea labeling is reduced by this amount the "corrected" urea labeling without hormone is only a small percentage and the value for $k_{8}$ is markedly increased. This correction will have a much smaller affect on $k_{s}$ when urea labeling is high in the bladder treated with hormone.

2. The inulin space on the serosal surface averages approximately 40 per cent of tissue water. This amount of tissue water is also very likely outside the permeability barrier, and its concentration of $\mathrm{C}^{14}$-urea probably approaches that of the serosal bathing medium, and hence may be close to zero. Consequently the concentration of urea between the permeability barriers may actually be up to 40 per cent greater than is calculated.

3 . The labeling of whole bladder water of greater than 100 per cent adds uncertainty to the concentration of free $\mathrm{C}^{14}$-urea in the intracellular water in the mucosal labeling experiments.

Because of these factors absolute values for the individual permeability coefficients $k_{m}$ and $k_{s}$ before and after hormone, can not be calculated with confidence. However, taking into account the complicating factors, an estimate of the relative change occurring in $k_{m}$ and $k_{s}$ upon the administration of the hormone can be made. Subtracting the average mucosal inulin space ( 7 per cent) from the average per cent labeling with urea before (11 per cent) and after (38 per cent) hormone, corrected values of 4 per cent before and 31 per cent after are obtained. Substituting these figures into the appropriate equations gives $\mathrm{k}_{\mathrm{m}}$, $19 \times 10^{-7} \mathrm{~cm}$ per second before, and $477 \times 10^{-7}$ $\mathrm{cm}$ per second after, or an increase in the range of 25 -fold; and $\mathrm{k}_{\mathrm{s}}, 450 \times 10^{-7} \mathrm{~cm}$ per second before, and $1,061 \times 10^{-7} \mathrm{~cm}$ per second after, or an increase of possibly twofold. Correcting for the serosal inulin space would not change the relative increase of $k_{s}$ and would increase still further that of $\mathrm{k}_{\mathrm{m}}$.

Thus the action of hormone on the permeability barriers of the toad bladder to urea can be characterized as follows: when the hormone is absent, the low transmembrane penetration of urea is due 
primarily to the relative impermeability of a mucosal barrier. When hormone is added to the serosal surface, the permeability of this mucosal barrier increases strikingly and a large increase in transmembrane permeability to urea results. Whether in addition, a much smaller relative increase in permeability of the serosal surface contributes to the large post-hormonal transmembrane permeability cannot be ruled in or out on the basis of the present studies.

It seems entirely possible that the mucosal action of the hormone may prove to be its sole action not only with respect to urea but also in the case of other substances whose permeability it affects, notably water and sodium. Preliminary studies employing tritium-labeled water show a significant increase in tissue water labeling across the mucosal barrier following hormone, again indicating an important change in mucosal permeability. A similar result has been obtained with sodium; here, however interpretation is more difficult, since sodium is a charged particle, and its concentration in tissue water following hormone may be affected by changes in electrical potentials across the cell membranes as well as by changes in membrane permeability.

The mucosal site of action of the hormone is all the more striking when one considers that the hormone acts only when it is added to the serosal bathing medium. This may simply be another consequence of the impermeability of the mucosal surface which prevents access of the hormone to its site of action from that side.

At the present time the action of the hormone appears to affect the permeability to only a few substances: sodium, water, urea and certain analogs of the latter. The lack of an effect on thiourea emphasizes the specificity of the permeability changes induced in the membrane by the hormone. An important property common to water, urea and acetamide, but not to thiourea, is the marked propensity of the former group to undergo hydrogen bonding. Recently, Stein and Danielli (29) and Stein (30) have presented evidence that hydrogen bonding accounts for the facilitated diffusion of glycerol through the membranes of red blood cells. They postulate that, in the red cell, bimolecular protein layers penetrate through the double lipid layer comprising the cell membrane. These bimolecular protein layers could thus serve as chan- nels accessible to compounds whose ability to hydrogen bond allows them to slip between the two layers of hydrogen-bonded protein molecules. According to this view the action of the hormone might be to open such protein-lined channels at the mucosal surface making them available for entry by suitable molecules. As mentioned, the present study failed to test critically for any mechanism of penetration which is dependent upon hydrogen bonding. Furthermore, how this view may be reconciled with evidence for bulk flow of water through this membrane (31) and how the sodium ion can have access to such channels, are problems which remain unresolved by this view of the membrane.

Andersen and Ussing (12) observed a marked augmentation of the permeability of the isolated skin of the toad, Bufo bufo, to thiourea after treatment with neurohypophyseal hormones. This finding is in apparent contradiction to our failure to observe any change in permeability of the toad bladder to thiourea following hormone. However, when the effect of hormone on the isolated skin of the toad, Bufo marinus, used in the present study, was tested with respect to urea, thiourea and sodium, no effect on either urea or thiourea permeability was observed, although the usual large stimulation of sodium transport occurred. This emphasizes the differences which may exist in analogous membranes from closely related species.

The increased permeability of the toad bladder to urea in the presence of neurohypophyseal hormones may have importance for the water economy of the animal. Ewer (32) first noted that the large volume of fluid contained within the urinary bladder of the toad served as a reserve supply of water which was rapidly reabsorbed during dehydration or following administration of mammalian posterior pituitary extracts. Such fluid reabsorption in response to hormone requires the presence of an osmotic gradient across the membrane, as has been shown for the frog and toad skins $(11,33)$ and recently by Bentley (34) for the toad bladder in vitro. Active sodium reabsorption will reduce urine osmolality and afford the requisite osmotic gradient. In the well hydrated toad, final urine sodium concentrations of only a few milliequivalents per liter have been found with dilute urines of 50 to $100 \mathrm{mOsm}$ per $\mathrm{kg}$ water (13). Of the solute now contributing to the 
urine osmolality, 50 per cent may be urea, and its concentration in the urine considerably exceeds that in the serum. If an action of neurohypophyseal hormone, in addition to facilitating water reabsorption from such a urine, were to increase the permeability of the bladder to urea as well, then back diffusion of urea through the bladder wall would serve to sustain the osmotic gradient for reabsorption of water. This would result in a considerable economy of water to the toad: at the expense of an elevation of blood urea. Table VI shows that the dehydrated toad excretes a urine essentially isosmotic with its serum and that the urine urea and serum urea concentrations become equal. Hence diffusion equilibrium is attained between urine and serum for both water and urea.

The saving in water to the animal by this reabsorption of urea can be estimated. If urea were impenetrant, approximately 75 per cent of the water in the bladder could be reabsorbed before the osmotic effect of retained urea and other urinary solutes would prevent further reabsorption of water. With urea also moving out of the bladder, this figure would rise to 95 per cent, or a 20 per cent gain of water reabsorbed. Regarded in terms of the water remaining unavailable in the bladder, this represents a reduction of 80 per cent in the water lost to the toad by urination.

Similar considerations may apply to the more complex mammalian renal tubule. Klümper, Ullrich and Hilger (23) and Levinsky and Berliner (4) have recently offered evidence that, during the elaboration of concentrated urine, both water and urea leave the collecting tubule. The concentration of urea in the medullary interstitial fluid increases thereby and balances osmotically its concentration in the collecting tubule. Thus, a high permeability to urea postulated for the collecting tubule epithelium allows urea to equilibrate on the two sides of the epithelium and the high nonurea solute concentration of the medullary interstitial fluid can exert its full osmotic force to concentrate the nonurea solute of the urine.

The high permeability of the collecting tubule to urea, necessary for such equilibration to occur during antidiuresis, may result from a direct action of antidiuretic hormone. The increased back reabsorption of urea which occurs during antidiuresis has been attributed in the past to the lower rate of urine flow, and the possibility of an additional effect of antidiuretic hormone on the permeability of the mammalian renal tubule to urea has not as yet been definitely shown, but is suggested by observations of Shannon (35). He found that the ratio of the urea to creatinine clearances may be depressed as low as 0.20 in dogs deprived of water for at least 24 hours, whereas this ratio was 0.55 to 0.65 at similar rates of urine flow from dogs that were less dehydrated and in which presumably lower levels of circulating antidiuretic hormone existed. It remains to be determined whether neurohypophyseal hormones directly affect the permeability of the mammalian renal tubule to urea as has been demonstrated in this study for the isolated toad bladder.

\section{SUM MARY}

1. The effect of mammalian neurohypophyseal hormones on the permeability of the isolated toad bladder to urea has been determined.

2. The hormone added to the serosal bathing medium increases the permeability coefficient from $26 \pm 2.5$ (SE) $\times 10^{-7} \mathrm{~cm}$ per second to $274 \pm$ $3.8(\mathrm{SE}) \times 10^{-7} \mathrm{~cm}$ per second.

3. The permeabilities measured simultaneously in the two directions across the membrane with $\mathrm{C}^{14}$ - and $\mathrm{N}^{15}$-urea, respectively, were found equal both in the presence and absence of hormone. This indicates that urea moves passively through the bladder.

4. No evidence of self-depression of the permeability to urea was detected with concentrations of urea in the medium up to 50 mmoles. Although this suggests that there is no carrier-mediated transport through the tissue, it would not exclude the possibility of such transport if urea were hydrogen-bonded to the "carrier."

5. Although the hormonal action on urea permeability affects a passive process, its action, nevertheless, is highly specific. This is illustrated by the absence of an effect of the hormone on the permeability of the bladder to thiourea.

6 . The increase in permeability of the membrane to urea following hormone can be largely, if not entirely, accounted for by an action of the hormone to increase the permeability of a diffusion barrier at the mucosal surface of the membrane.

\section{REFERENCES}

1. Hargitay, B., and Kuhn, W. Das Multiplikationsprinzip als Grundlage der Harnkonzentrierung in der Niere. Z. Elektrochem. 1951, 55, 539. 
2. Miles, B. E., Paton, A., and de Wardener, H. E. Maximum urine concentration. Brit. med. J. 1954, 2, 901.

3. Epstein, F. K., Gleeman, C. R., Pursel, S., and Hendrikx, A. The effect of feeding protein and urea on the renal concentrating process. J. clin. Invest. 1957, 36, 635.

4. Levinsky, N. G., and Berliner, R. W. The role of urea in the urine concentrating mechanism. J. clin. Invest. 1959, 38, 741.

5. Crawford, J. D., Doyle, A. P., and Probst, J. H. Service of urea in renal water conservation. Amer. J. Physiol. 1959, 196, 545.

6. Marshall, E. K., Jr., and Crane, M. M. The secretory function of the renal tubules. Amer. J. Physiol. 1924, 70, 465.

7. Forster, R. P. Active cellular transport of urea by frog renal tubules. Amer. J. Physiol. 1954, 179, 372.

8. Love, J. K., and Lifson, N. Transtubular movements of urea in the perfused bullfrog kidney. Fed. Proc. 1958, 17, 100.

9. Ussing, H. H., and Zerahn, K. Active transport of sodium as the source of electric current in the short-circuited isolated frog skin. Acta physiol. scand. 1951, 23, 110.

10. Ussing, H. H. The distinction by means of tracers between active transport and diffusion. The transfer of iodide across the isolated frog skin. Acta physiol. scand. 1949, 19, 43.

11. Koefoed-Johnsen, V., and Ussing, H. H. The contributions of diffusion and flow to the passage of $\mathrm{D}_{2} \mathrm{O}$ through living membranes. Effect of neurohypophyseal hormone on isolated anuran skin. Acta physiol. scand. 1953, 28, 60.

12. Andersen, B., and Ussing, H. H. Solvent drag on non-electrolytes during osmotic flow through isolated toad skin and its response to antidiuretic hormone. Acta physiol. scand. 1957, 39, 228.

13. Leaf, A., Anderson, J., and Page, L. B. Active sodium transport by the isolated toad bladder. J. gen. Physiol. 1958, 41, 657.

14. Sprinson, D. B., and Rittenberg, D. The rate of utilization of ammonia for protein synthesis. J. biol. Chem. 1949, 180, 707.

15. Leaf, A. Measurement of the permeability of the two surfaces of a living membrane. Science 1958, 128,144

16. Leaf, A. The mechanism of the asymmetrical distribution of endogenous lactate about the isolated toad bladder. J. cell. comp. Physiol. 1959, 54, 103.

17. Parpart, A. K., and Shull, J. C. Solvent water in the normal mammalian erythrocyte. J. cell. comp. Physiol. 1935, 6, 137.

18. Bozler, E. Osmotic effects and diffusion of nonelectrolytes in muscle. Amer. J. Physiol. 1959, 197, 505.
19. Schmidt-Nielsen, B. Urea excretion in mammals. Physiol. Rev. 1958, 38, 139.

20. Smith, H. W. Absorption and excretion of water and salts by the elasmobranch fishes. II. Amer. J. Physiol. 1931, 98, 296.

21. Rehberg, P. B. Studies on kidney function. II. The excretion of urea and chlorine analysed according to a modified filtration-reabsorption theory. Biochem. J. 1926, 20, 461.

22. Chasis, H., and Smith, H. W. The excretion of urea in normal man and in subjects with glomerulonephritis. J. clin. Invest. 1938, 17, 347.

23. Klümper, J. D., Ullrich, K. J., and Hilger, H. H. Das Verhalten des Harnstoffs in den Sammelrohren der Säugetierniere. Pflüg. Arch. ges. Physiol. 1958, 267, 238.

24. Pauling, L. The Nature of the Chemical Bond, 2nd ed. London, Oxford University Press, 1948, p. 315.

25. Kay, C. M., and Edsall, J. T. Dimerization of mercaptalbumin in presence of mercurials. III. Bovine mercaptalbumin in water and in concentrated urea solutions. Arch. Biochem. 1956, 65, 354.

26. Collander, R., and Bärlund, H. Permeabilitäts Studien an chara ceratophyllia. Acta botanica fenn. 1933, 11, 1.

27. Gosting, L. J., and Akeley, D. F. A study of the diffusion of urea in water at $25^{\circ}$ with the Gouy interference method. J. Amer. chem. Soc. 1952, 74, 2058.

28. Wang, J. H., Robinson, C. V., and Edelman, I. S. Self-diffusion and structure of liquid water. III. Measurement of the self-diffusion of liquid water with $\mathrm{H}^{2}, \mathrm{H}^{3}$, and $\mathrm{O}^{18}$ as tracers. J. Amer. chem. Soc. 1953, 75, 466.

29. Stein, W. D., and Danielli, J. F. Structure and function in red cell permeability in Membrane Phenomena, A General Discussion of the Faraday Society. Aberdeen, The University Press, 1956, p. 250.

30. Stein, W. D. N-terminal histidine at the active centre of a permeability mechanism. Nature (Lond.) 1958, 181, 1662.

31. Hays, R. Unpublished data.

32. Ewer, R. F. The effect of pituitrin on fluid distribution in Bufo regularis Reuss. J. exp. Biol. 1952, 29, 173.

33. Sawyer, W. H. Effect of posterior pituitary extract on permeability of frog skin to water. Amer. J. Physiol. 1951, 164, 44.

34. Bentley, P. J. The effects of neurohypophyseal extracts on water transfer across the wall of the isolated urinary bladder of the toad Bufo marinus. J. Endocr. 1958, 17, 201.

35. Shannon, J. A. Glomerular filtration and urea excretion in relation to urine flow in the dog. Amer. J. Physiol. 1936, 117, 206. 